\title{
HÉRNIA DE SPIEGEL À ESQUERDA: DESCRIÇÃO DE CASO CLÍNICO E ANÁLISE DA LITERATURA
}

\section{SPIEGEL'S HERNIA ON THE LEFT: CLINICAL CASE DESCRIPTION AND LITERATURE REVIEW}

Daiany Pereira de Castro ${ }^{1}$, Lara Inês Martins Dantas ${ }^{1}$, Romeu Francisco Maia Ames $^{1}$, Sophia Machado Ayres Sardinha ${ }^{1}$, Anna Paula Silva Nogueira ${ }^{1}$, Monalisa Marques Gervásio ${ }^{1}$, Viviane Tiemi Kenmoti ${ }^{2}$

\begin{abstract}
RESUMO
Introdução: As hérnias de Spiegel (HS) é um defeito raro da parede abdominal, correspondendo com diagnóstico particularmente difícil pelo quadro clínico vago. Normalmente têm indicação cirúrgica pelo risco de encarceramento e estrangulamento. Descrição do caso: Paciente feminino, 55 anos com abaulamento em região abdominal esquerda, que evoluiu no ultimo ano com dor intensa, acompanhada de náuseas e esporadicamente síncope. O diagnóstico de hérnia de Spiegel à esquerda foi confirmado pelo USG. A conduta escolhida foi a hernioplastia de Spiegel em decúbito dorsal horizontal sob raquianestesia, com fixação da tela de Marlex. Considerações finais: Este caso mostrou a relevância, ao ter a hérnia de Spigel como diagnostico diferencial, frente à clínica de dor ao longo da aponeurose de Spiegel, e da importância de exames de imagem para o diagnóstico.

Palavras-chave: Hérnia Abdominal; Aponeurose; Herniorrafia;
\end{abstract}

RFM, Sardinha SMA, Nogueira APS, Gervásia MM, Kenmoti VT.(2021) Hérnia de spiegel à esquerda: descrição de caso clínico e análise da literatura. Revista de Patologia do Tocantins, 8(1).

Instituição: ${ }^{1}$ Discente do curso de medicina do Instituto Tocantinense Presidente Antônio Carlos- ITPAC/Porto; ${ }^{2}$ Médica cirurgiã geral e coloproctologista, professora da disciplina clínica cirúrgica do Instituto Tocantinense Presidente Antônio Carlos - ITPAC.

Autor correspondente: Daiany Pereira de Castro $^{1}$ (Autor de Correspondência) (Fapac - Faculdade Presidente Antônio Carlos Porto Nacional, Tocantins, Brasil; Endereço: Rua Maria Angelica da Silva Prado, Qd- 25, Lt- 08, no 1594; telefone: (63) 98517-4073; e-mail: daianycastro01@hotmail.com)

Editor: Carvalho A. A. B. Medicina, Universidade Federal do Tocantins, Brasil.

Publicado: 12 de maio de 2021.

Direitos Autorais: (c) 2021 Castro et al. Este é um artigo de acesso aberto que permite o uso, a distribuição e a reprodução sem restrições em qualquer meio, desde que o autor original e a fonte sejam creditados.

Conflito de interesses: os autores declararam que não existem conflitos de interesses.

\begin{abstract}
Introduction: Spiegel hernias (HS) is a rare defect of the abdominal wall, corresponding to a diagnosis that is particularly difficult due to the vague clinical picture. They are usually indicated for surgery due to the risk of incarceration and strangulation. Case description: Female patient, 55 years old with bulging in the left abdominal region, who developed in the last year with severe pain, accompanied by nausea and sporadically syncope. The diagnosis of Spiegel's hernia on the left was confirmed by USG. The chosen approach was Spiegel's hernioplasty in the supine position under spinal anesthesia, with fixation of the Marlex mesh. Final considerations: This case showed the relevance of having Spigel's hernia as a differential diagnosis, compared to the pain clinic along Spiegel's aponeurosis, and the importance of imaging tests for diagnosis.

key-words: Hernia Abdominal; Aponeurosis; Herniorrhaphy;
\end{abstract}




\section{INTRODUÇÃO}

As hérnias de Spiegel (HS) apresentam-se como um defeito da parede abdominal, ocorrendo através da aponeurose spigeliana, entre a linha semilunar (que marca a transição do músculo para a aponeurose no músculo transverso abdominal) e a borda lateral do músculo reto, logo abaixo da linha arqueada de Douglas e, geralmente, acima dos vasos epigástricos superiores, em zona denominada de o "cinturão da hérnia spigeliana".Na maioria dos casos, a HS contém intestino delgado, cólon sigmóide, cólon transverso, ceco, apêndice, ou divertículo de Meckel $^{1}$.

Estas hérnias são raras correspondendo a 1-2\% das hérnias da parede abdominal anterior ${ }^{1,2}$. O diagnóstico clínico é considerado difícil, pois as dimensões do saco herniário (normalmente pequeno) e sua localização, que na maioria da vezes, se encontra inferior à aponeurose do músculo oblíquo externo, dificultam o aparecimento de sinais e sintomas característicos no exame clínico, sendo que e a hérnia pode ser intraparietal, sem massa evidente à inspeção ou palpação ${ }^{1}$.

A ecografia pode auxiliar no diagnóstico, além de realizar o diagnóstico diferencial em relação a outras patologias (apendicite e abcesso apendicular, neoformação da parede abdominal e hematoma espontâneo da bainha dos retos) $)^{1,2}$. Com a confirmação do diagnóstico, o tratamento normalmente é cirúrgico, pelo risco de encarceramento e de estrangulamento. As hérnias de Spiegel bilaterais são muito raras com poucos relatos na literatura mundial ${ }^{2}$. O objetivo deste artigo é descrever o caso cínico de uma hérnia de Spiegel e analisar a abordagem da literatura sobre essa patologia.

\section{DESCRIÇÃO DO CASO}

Paciente feminino, 55 anos relatou dor de leve intensidade e abaulamento em região abdominal esquerda, que reduz sem necessidade de manobra manual, com inicio do quadro há oito anos. No último ano evoluiu com dor intensa, acompanhada de náuseas e esporadicamente síncope. $\mathrm{Na}$ história pessoal nega comorbidades e foi submetida à colecistectomia e laqueadura. Ao exame físico apresentava abdômen globoso, flácido, sem dor a palpação superficial e profunda e com abaulamento em região de fossa ilíaca esquerda (FIGURA 1).

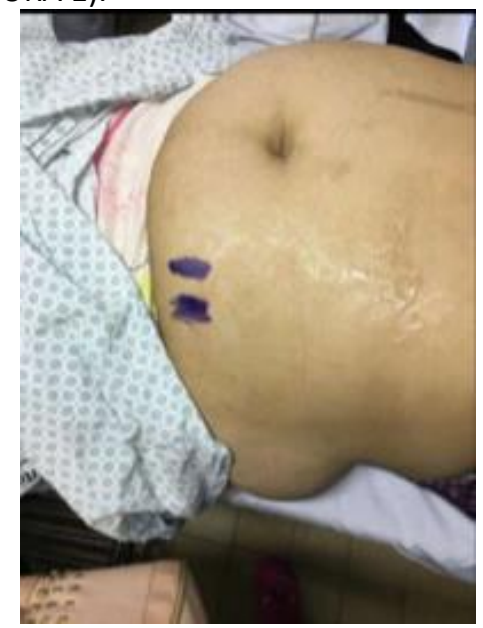

Foi solicitado o ultrassom de parede abdominal que confirmou o diagnóstico de hérnia de Spiegel à esquerda. A conduta escolhida foi a hernioplastia de Spiegel em decúbito dorsal horizontal sob raquianestesia, com incisão transversal em flanco esquerdo associada à dissecção por planos. Durante o procedimento foi identificada falha na musculatura abdominal com presença de gordura pré-peritoneal, que foi dissecada e invaginada para cavidade peritoneal. Ainda, foi realizado sutura da musculatura com fixação da tela de Marlex, sendo finalizado o procedimento com sutura da aponeurose e fechamento por planos (FIGURA 2). A paciente progrediu bem, sem nenhuma intercorrência recebendo alta no 2으 dia de pós-operatório.

\section{DISCUSSÃO}

A hérnia de spigel é uma entidade rara, geralmente adquirida na quarta década de vida apresentando sintomas inespecíficos, sendo a dor o mais comum deles e que varia de acordo com cada paciente, o que torna o diagnostico clínico difícil. Por isso pequenas hérnias costumam ser negligenciadas e confundidas com hematoma do músculo reto abdominal, seroma e abscesso abdominal, que são diagnósticos diferenciais importantes para esse tipo de hérnia ${ }^{3,4}$.

Devido a essas outras possibilidades recomenda-se o uso da ultrassonografia para a verificação do diagnostico. Outra opção de exame de imagem para auxiliar na confirmação do diagnostico, seria a tomografia computadorizada, que fornece mais informações sobre o conteúdo do saco herniário ${ }^{5}$.

Após a confirmação do diagnostico é necessário realizar tratamento cirúrgico, devido ao alto índice de complicação como encarceramento e estrangulamento (21-33\%). Há poucos estudos que comparam as diferentes técnicas cirúrgicas. Mas em geral é sugerido o uso de prótese sintética por garantir maior força e resistência, levando consequentemente a melhores resultados do que um fechamento simples ${ }^{5,6}$.

Já em relação à abordagem cirúrgica para a colocação da tela há a opção de hernioplastia aberta ou laparoscopia, nenhuma se mostrou superior à outra, assim a escolha deve ser baseada nas particularidades do doente e da hérnia, nos meios técnicos disponíveis pelo hospital e na experiência do cirurgião. Além disso, a colocação da tela está relacionada a um menor risco de recidiva ${ }^{5,6}$. Este caso mostrou a relevância, ao ter a hérnia de Spigel como diagnostico diferencial, frente à clínica de dor ao longo da aponeurose de Spiegel, e da importância de exames de imagem para o diagnóstico de HS.

\section{REFERÊNCIAS BIBLIOGRÁFICAS}

1. Vieira, V. C. S., Vieira, R. R. B. T., Alves, T. B., de Souza, A. G., de Paula, J. F., Batista, C. A. M. Hérnia de Spiegel: Relato de dois Casos. Revista de Saúde. 2016, 7(2), 26-30.

2. Chaib P. S., Coltri R. P., Castro M. M. O. Hérnia de Spiegel bilateral volumosa. Relatos Casos Cir. 2017, (4):1-5.

3. Di Tommaso, R. A. D. S., da Silva Neto, R. A., Ballut, P. C., Bergamasco, J. J. C., dos Santos, M. H., Hagiwara, T. Hérnia de spiegel: relato de caso. Da revista em português inglês. 2014, 13(1). 
4. Vieira, V. C. S., Tavares Vieira, R. R. B., Alves, T. B., de Souza, A. G., de Paula, J. F., Marques Batista, C. A. Hérnia de Spiegel: Relato de dois Casos. Revista De Saúde. 2016, 7(2), 26-30.

5. Alves, B. B., Neri, A. C. A. A. A., de Sá Silva, J. J., de Paula, J. F., Batista, C. A. M. Hérnia de spiegel relato de caso. Saber Digital. 2018, 11(2), 85-93.

6. Goulart, A., Marques, H., Reis, M. Hérnia de Spiegel: descrição de caso clínico com análise da literatura. Revista Portuguesa de Cirurgia. 2015, (35), 41-47. 